\title{
Хай-тек vs COVID-19...
}

\author{
М. Макушин ${ }^{1}$, и. Черепанов ${ }^{2}$
}

УДК 621.38 | ВАК 05.11.17

\begin{abstract}
Всемирная организация здравоохранения объявила пневмонию COVID-2019, вызываемую вирусом SARS-CoV-2, глобальной пандемией. Есть ли у человечества высокотехнологичный ответ этому вызову? Да. Это методы диагностики и лечения, дезинфекции, разрабатываются лекарственные средства и вакцины, специфичные к COVID-19. Развитие высокотехнологичных отраслей промышленности дошло до такого этапа, когда прорывы совершаются скорее не в узко-специализированной области, а на стыке нескольких научных дисциплин и производственных технологий. В борьбе с пандемией объединяются усилия специалистов в области вирусологии, микробиологии, микросистемной техники, электроники и т.д.
\end{abstract}

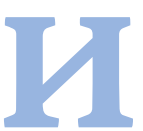

нформация о пандемии пневмонии COVID-2019, вызываемой коронавирусом SARS-CoV-2, по-прежнему заполняет ленты новостных агентств. Реакцию электронной промышленности на это событие можно условно рассматривать по нескольким направлениям: создание средств диагностики и лечения, изменение бизнесмоделей, использование ситуации в своих целях и т. п.

К средствам диагностики можно отнести тепловидение, компьютерную томографию и приборы тестирования на вирус. Одним из важнейших типов оборудования, используемого при лечении больных, являются аппараты искусственной вентиляции легких (ИВЛ). В качестве средств обеззараживания электронная промышленность в основном предлагает приборы на основе ультрафиолетовых светодиодов (УФ СИД).

Эпидемия COVID-19 в КHР, по всей видимости, преодолена. Так, в г. Шэньчжэнь (провинция Гуандун, юг страны), одном из крупнейших производственных комплексов электроники, с 24 февраля начали возобновлять работу промышленные предприятия [1]. К концу марта были сняты ограничения в эпицентре пандемии г. Ухань (провинции хубэй, центральный Китай). Однако сохраняется возможность второй волны заболевания - осенью.

За пределами КНР многие электронные фирмы пересматривают прогнозы своих прибылей на 2020 год. Так уже сделали корпорации Broadcom (Сан-Хосе, шт. Калифорния) и Infineon (Мюнхен, ФРГ), a Applied Materials (Санта-Клара, шт. Калифорния), NXP Semiconductors (Эйндховен, Нидерланды) и ON Semiconductor (Феникс, шт. Аризона) сообщили об ожидающемся сокращении доходов за I кв. текущего года. Infineon, например, ожидает падения доходов за I кв. на 50-150 млн долл. Нижняя граница отражает сложившуюся ситуацию, а верхняя - ожидания в случае ее ухудшения.

ЦНИИ «Электроника», главный специалист, mmackushin@gmail.com. цнии «электроника», главный специалист.
У корпорации On Semiconductor аналогичные предположения - снижение продаж до 1,275-1,325 млрд долл. по сравнению с более ранними оценками в 1,355-1,405 млрд долл. [2] . После введения с 17 марта ограничений по COVID-19 во Франции корпорация STMicroelectronics (Женева, Швейцария) объявила о временной приостановке деятельности, что коснется 50\% занятых. Возможна задержка с вводом в строй опытной линии по производству GaN приборов в г. Тур [3]. Подобных примеров сейчас великое множество.

\section{ДЕЯТЕЛЬНОСТЬ ОРГАНОВ ВЛАСТИ}

Если оставить за скобками карантинные мероприятия, то, с точки зрения организации производства необходимого оборудования и применения лекарственных средств, можно отметить два примера из деятельности американских властей. Так, президент США Дональд Трамп начал применять закон "Об оборонной промышленности» (Defense Production Act, DPA, 1950 г. с последующими изменениями и дополнениями). Этот закон позволяет правительству контролировать цены, объемы производства, заработной платы и др. Также он предусматривает контроль за экономическими параметрами в целях обеспечения национальной безопасности, изъятие собственности в целях национальной безопасности, требование от предприятий приоритетного исполнения ими контрактов и заказов, связанных с обороной и т.д. Несмотря на повышенную потребность почти во всех видах медицинского снабжения - от перчаток до масок, от тест-наборов до лекарств и аппаратов искусственной вентиляции легких, Трамп использовал DPA пока только один раз - 27 марта 2020 года он приказал корпорации General Motors немедленно приступить к производству аппаратов Ивл [4].

Кроме того, Управление по контролю качества пищевых продуктов и медикаментов (FDA) Министерства здравоохранения и социальных услуг США активно 
использует практику выдачи «Разрешений на использование лекарственных препаратов в чрезвычайных ситуациях" (Emergency Use Authorization, EUA). Это временные разрешения в процессе утверждения новых лекарств или новых показаний к ранее одобренным препаратам на их применение во время объявленной чрезвычайной ситуации (до завершения полного цикла процесса утверждения этих препаратов или их новых показаний) [5].

\section{ЭКОНОМИЧЕСКИЕ ПОСЛЕДСТВИЯ}

По данной тематикеуже издаются специализированные исследования. Так, корпорация International Data Corporation (IDC, Фремингем, шт. Массачусетс) провела исследование «Влияние COVID-19 на прогноз мирового рынка полупроводниковых приборов" (Impact of COVID-19 on the Worldwide Semiconductor Market Forecast), в котором представлена методика оценки воздействия пандемии на рынок с использованием четырех сценариев, оценивающих диапазон возможных результатов. Каждый сценарий основан на различных предположениях и степени серьезности воздействия COVID-19 на деятельность высокотехнологичных фирм. Для каждого сценария выбран ряд критических факторов для формирования обновленного прогноза [6]. Также по данным IDC расходы конечных пользователей в 2020 году на ИТ-инфраструктуру (серверные и корпоративные системы хранения данных) сократятся. При текущем вероятном сценарии продажи серверов снизятся на 3,4\% (88,6 млрд долл.), а расходы на закупку внешних корпоративных систем хранения данных (external enterprise storage systems, ESS) снизятся на 5,5\% (до 28,7 млрд долл.) [7].

Аналогичного подхода придерживается исследовательская фирма Juniper Research (Саннивэйл, шт. Калифорния), прогнозирующая возможное сокращение продаж интеллектуальныхприборов примерно на 42 млрд долл. в течение следующих девяти месяцев. В рамках проведенного анализа был изучен ряд основных вертикально-интегрированных цепочек поставок, обеспечивающих изготовление таких конечных электронных систем, как смартфоны, планшетные ПК, потребительская робототехника, умные динамики и интеллектуальная носимая электроника. По результатам исследования сформулированы три сценария возможного развития ситуации, отражающие слабое, среднее и сильное воздействие на рынок последствий пандемии COVID-2019 [8].

\section{Сокращение производства}

Отмечается, что в случае сильного воздействия пандемии на рынок в ближайшие девять месяцев производство смарт-приборов сократится более чем на 80 млн шт. Причиной станут возможные задержки поставок и/или дефицит таких компонентов, как процессоры, дисплеи, источники питания и т.д. Все это может привести к срыву темпов производства у конечных поставщиков, включая корпорации Apple, Samsung, Amazon, Xiaomi и Huawei. Все они должны быть готовы к заполнению любых прорывов в их цепочках поставок - для удовлетворения спроса на их продукцию.

Также прогнозируется, что на смартфоны в течение следующих девяти месяцев будет приходиться большая часть дефицита смарт-приборов, что составляет более 85\% возможных недопоставок. Предполагается, что вирус может также вызвать более долгосрочные проблемы, в том числе затруднения при разработке новых приборов и конечных электронных систем. Кроме того, финансовая неопределенность от воздействия вируса означает, что спрос будет ниже, в результате чего поставщики не смогут полностью восстановить потери от продажи своей продукции.

\section{"Устойчивые" стратегии производителей}

Исследование Juniper Research показало, что производителям интеллектуальных приборов необходимо диверсифицировать базы поставщиков компонентов. Утверждается, что это позволит обеспечить заполнение возможных пробелов в цепочке поставок.

В модели "производство точно в срок» слабым звеном всегда была устойчивость цепочек поставок. Эта модель предполагает такую организацию цепочек поставок, которая обеспечивает своевременную поставку компонентов непосредственно перед этапом изготовления конечной системы. В качестве страховки работоспособности данной модели всегда создавался определенный объем товарно-материальных запасов. Но в современной ситуации, как полагают специалисты Juniper Research, обладание полным ассортиментом товарно-материальных запасов может оказаться слишком дорогостоящим, и теперь поставщики должны рассмотреть вопрос о создании перечня “стратегических» компонентов [8]

\section{Способы стимулирования производства}

Поставщики медицинского оборудования не только наращивают собственное производство аппаратов ИВЛ, но и делают многое, чтобы другие производители, не работавшие ранее на рынке медицинского оборудования, могли наладить свое собственное производство медицинской техники. Так, корпорация Medtronic выложила в открытый доступ документацию на аппарат ИВЛ РВ560: руководство по эксплуатации и обслуживанию, проектно-сметную и технологическую документацию, схемную документацию и технические условия на проектирование. Вскоре будут представлены программируемые коды и другая информация. Это предоставит широкому кругу производителей, изобретателей, стартапов и научных учреждений возможность быстрого проектирования новых конструкций ИВЛ и наращивания их производства.

Аппарат ИВЛ РВ560 не нов, он выпускается с 2010 года и сейчас продается в 35 странах мира. Но он прост, 
технологичен в производстве и отвечает современным требованиям борьбы с COVID-19 [9]. Чего в этом действии больше - благотворительности или желания, воспользовавшись ситуацией, распродать запасы нереализованной продукции и расширить круг пользователей своих технологий, сказать трудно.

\section{СРЕДСТВА ДИАГНОСТИКИ Тепловизоры}

Технология тепловидения была разработана сначала для военных, а затем для гражданских применений, таких как термография, средства наблюдения, пожаротушения, автомобильная электроника, охотничьи принадлежности и т.д. Повышенная температура тела человека, один из основных симптомов заболевания, легко контролируется с помощью тепловизоров, работающих в диапазоне волн от 8 до 14 мкм. Это помогает идентифицировать инфицированных среди огромных скоплений людей, например, в аэропортах, на вокзалахи т.д.

По данным исследования группы Yole Développement (Лион, Франция), в 2019 году было отгружено более 1,5 млн тепловизоров на сумму более 4,5 млрд долл. Предполагается, что мировой рынок тепловизоров увеличится с 4,3 млрд долл. в 2018 году до 6,7 млрд долл. в 2024-м (рис. 1)

Безусловно, в будущем тепловизоры получат более широкое распространение для повышения безопасности на границах, в аэропортах и т. п. Вероятно, к фирмамразработчикам тепловизоров, таким как FLIR, HikVision, Guide IR, Zhejiang Dali, Testo, Fluke и Seek Thermal, добавятся многие другие [10].

\section{ПЦР-методика: MEMS обеспечивают лучшие результаты}

В целом, следует отметить, что в настоящее время существует два типа средств тестирования. Это портативные/ переносные приборы, облегчающие диагностику по месту лечения ("у кровати больного", по месту обращения в амбулаторный/ первичный пункт оказания неотложной/скорой помощи - point of care, POC), а также стационарное

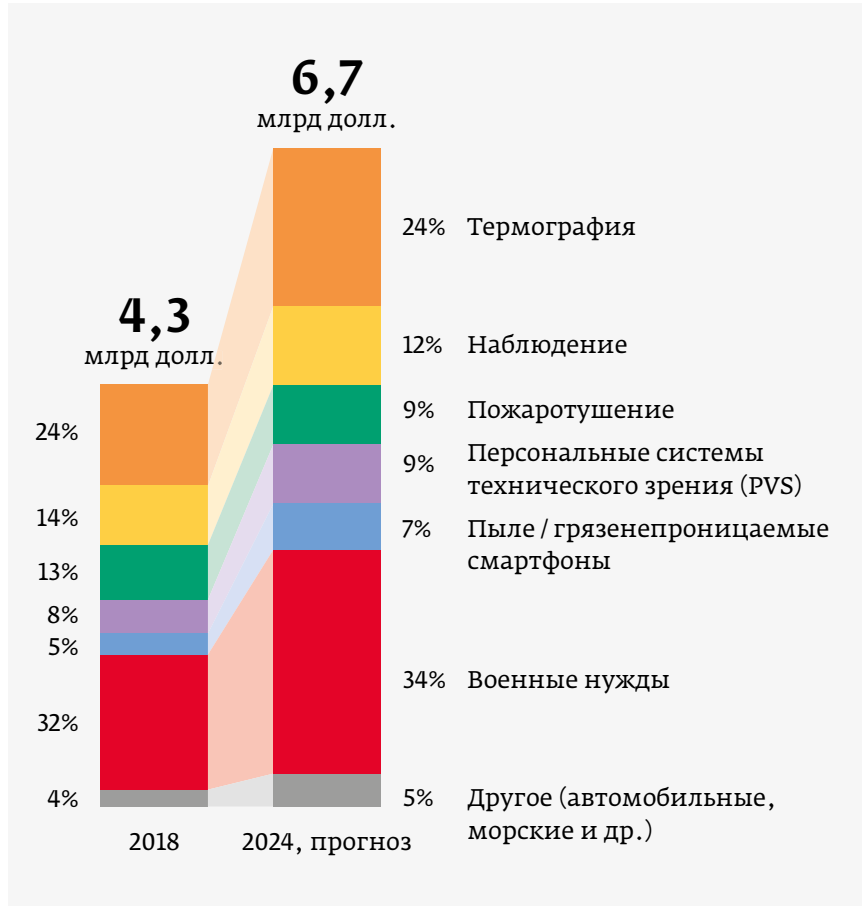

Рис. 1. Структура рынка тепловизоров в 2018 году и прогноз на 2024 год. Источник: Yole Développement

оборудование (используемое в клинических условиях, с жестким или колесно-стоечным монтажом) (табл. 1).

Первоначально в основе всех методов обнаружения виpyca SARS-CoV-2 лежал анализ обратной транскрипционной полимеразной цепной реакции (ОТ-ПЦР/ PCR) в реальном масштабе времени. Этот тест требует в первую очередь знания генома вируса. Результаты работ по секвенированию полного генома SARS-CoV-2 была впервые опубликована китайскими учеными 10 января 2020 года. После этого международной группе ученых, возглавляемой специалистами из ФРГ, потребовалось всего семь дней, чтобы опубликовать первый протокол тестирования образцов анализов пациентов, в настоящее время принятый ВО3. Уже ведется работа по обнаружению вируса с помощью других

Таблица 1. Последние разработки средств тестирования на COVID-19 [11-13]

\begin{tabular}{|c|c|c|}
\hline Фирма & Тип изделия & $\begin{array}{l}\text { Время тестирования } \\
\text { (в минутах) }\end{array}$ \\
\hline Abbott & $\begin{array}{l}\text { Abbott ID NOW тм COVID-19- } \\
\text { портативное средство тестирования на месте (осмотра) }\end{array}$ & $\begin{array}{l}\text { Положительные результаты - 5, } \\
\text { Отрицательные результаты - } 13\end{array}$ \\
\hline $\begin{array}{l}\text { BioFire Defense } \\
\text { (отделение компании } \\
\text { bioMérieux) }\end{array}$ & $\begin{array}{l}\text { BIOFIRE }{ }^{\oplus} \text { COVID-19 - } \\
\text { стационарное средство тестирования в лаборатории } \\
\text { среднего/высокого уровня сложности }\end{array}$ & 45 \\
\hline Mesa Biotech & $\begin{array}{l}\text { Accula SARS-CoV-2 - } \\
\text { портативное средство тестирования на месте (осмотра) }\end{array}$ & 30 \\
\hline
\end{tabular}


методов обнаружения, которые могут быть быстрее и дешевле в реализации, таких как тестирование на антитела или тесты CRISPR-Cas13.

Традиционные ПцР-средства обладают длительным циклом достижения результатов. Кроме того, они малочувствительны при низкой вирусной нагрузке в образце мазка тестируемых образцов, что может привести к значительному количеству ложноотрицательных результатов. Технология MEMS дает два основных преимущества для ПЦР: меньший размер по сравнению с обычными ПЦР-приборами и интеграция анализа содержимого множественных микропотоков. Обогреватели и реакционные MEMS камер обладают малой тепловой массой, что значительно ускоряет цикл нагрева-охлаждения и обеспечивает получение результата за считанные минуты. Интеграция микропотоков при обработке образцов и реагентов позволила создать новые методы, такие как цифровая ПцР (digital PCR) и микрокапельная цифровая ПЦР (Droplet dPCR, ddPCR). Такие приборы обеспечивают высокий уровень параллелизма операций тестирования, что позволяет существенно повысить чувствительность и сократить время тестирования. Результаты первоначального исследования (еще не подтвержденные дальнейшими клиническими испытаниями) показали, что ddPCR-прибор имеет в 500 раз меньший порог обнаружения SARS-CoV-2, чем у традиционных ПцР-приборов. Это означает, что когда образец пациента имеет низкую вирусную нагрузку, ddPCR-прибор имеет гораздо более высокий шанс правильно идентифицировать инфицированного пациента по сравнению с традиционной ПЦР.

Недавно сотрудники Исследовательского института электроники и телекоммуникаций и биотехнологической фирмы Genesystem (обе - г. Тэджон, Республика Корея) разработали прототип недорогой портативной системы ПЦР с полиимидной (полимерной) камерой, микронагревателем и встроенным КМОП-формирователем сигналов изображения для оптического считывания результатов (рис. 2).

Как бы это ни звучало, но пандемия COVID-19 открывает новые перспективы перед изготовителями MEMS и микропотоковых приборов, с одной стороны, а с другой - расширяет аналитический инструментарий медиков и биологов [5].

\section{Компьютерная томография}

Косвенный диагноз COVID-19 можно поставить с использованием компьютерной томографии (КT). Многие из тяжелых осложнений, вызванных COVID-19, возникают из-за пневмонии. Это можно увидеть на КТ как «затемнение по типу матового стекла», поэтому КТ использовалась в качестве диагностического инструмента на ранних этапах эпидемии в больницах в КНР, а теперь и по всему миру. Из-за своей высокой чувствительности КТ в настоящее время является методом визуализации, выбранным для диагностики и мониторинга пациентов с COVID-19. Объем продаж средств компьютерной томографии в 2018 году составил около 4 млрд долл., сейчас же рост их продаж предсказать трудно. Все основные поставщики КТ-сканеров работают в тесном сотрудничестве с больницами и правительственными ведомствами в различных странах мира. Такое взаимодействие позволяет облегчить установку новых КТ-сканеров и их использование на местах. Недавнее появление на этом рынке китайских игроков с более дешевыми системами может оказать существенное влияние на текущий кризис, особенно в развивающихся странах [10].

\section{СРЕДСТВА ЛЕЧЕНИЯ / УХОДА ЗА БОЛЬНЫМИ}

Наиболее часто в контексте борьбы с COVID-19 упоминаются аппараты ИВЛ, предназначенные для принудительной подачи газовой смеси (кислород и сжатый осушенный воздух) в легкие для насыщения крови кислородом и удаления из легких углекислого газа (табл. 2). Некоторые стационарные аппараты ИВЛ могут одновременно обслуживать несколько пациентов. В таких приборах, как правило, есть возможность индивидуальной подстройки режима вентиляции.

Однако безопасны ли сами ИВЛ? По данным Forbes, в Нью-Йорке до 80\% погибших от пандемии были подключены к аппаратам ИВЛ. К подобным сообщениям следует относиться осторожно. Во-первых, к ИВЛ подключают наиболее тяжелых больных, а в этой категории смертность всегда намного выше, чем в среднем. Во-вторых, неожиданно

КмОП-формирователь сигналов изображения Полимерная технологическая камера с пятью колодцами и СИД

Полимерный нагревательный модуль
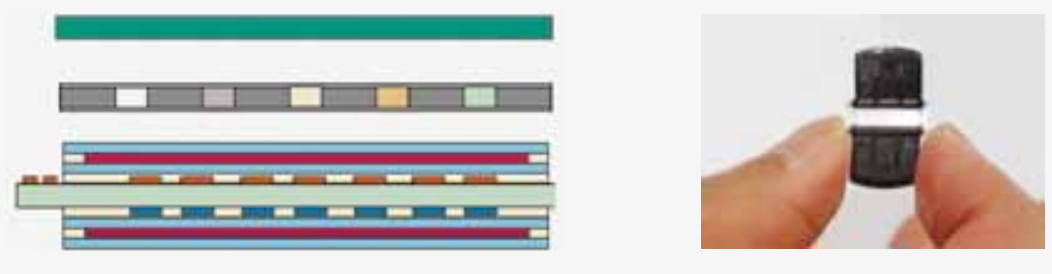

Рис. 2. Схема опытного образца недорогой портативной ПцР-системы на основе микросистемной технологии (слева) и система, встроенная в тестовый картридж (справа) 
широкое использование аппаратов ИВЛ привело к тому, что их не всегда используют подготовленные к этому врачи, а для ослабленных болезнью пациентов крайне важна правильная настройка аппарата ИВЛ. Так что дело не столько в самой технике, сколько в ее использовании. Кроме того есть вопросы стерилизации и т.д. [14].

Важным средством оптимизации работы аппаратов ИВЛ может стать технология "цифровых двойников". Недавно корпорации OnScale и LEXMA приступили к совместным работам по созданию индивидуальных "цифровых двойников» легких пациентов, которые могут точно предсказать уровень насыщенности крови кислородом и скорость кровотока. Это существенно поможет врачам принимать критические решения относительно использования аппаратов ИВЛ. Каждый “цифровой двойник» содержит данные компьютерной томографии и рентгенографии, наборы данных моделирования воздушного потока и кровотока в легких, обновляемые в реальном масштабе времени. Для повышения скорости и точности прогнозирования используются средства искусственного интеллекта, обученные по моделируемым и измеренным данным пациента [15].

\section{СРЕДСТВА ДЕЗИНФЕКЦИИ / СТЕРИЛИЗАЦИИ}

Если говорить о мерах дезинфекции, то самой распространенной практикой является использование химических средств. Еще один вариант дезинфекции - использование коротковолновых УФ-СИД (ультрафиолет С, УФ-С, длина волны излучения 280-100 нм) и СИД, работающих в дальней УФ-области спектра (ДУФ, длина волны излучения 122-200 нм).

Таблица 2. Некоторые аппараты ивл [16-19]
Ультрафиолетовое излучение обладает способностью убивать вирусы и бактерии, разрушая их ДНК, а также может использоваться для стерилизации. Наиболее эффективны в этом плане по мощности излучения и компактности - приборы и системы на основе УФ-С СИД. В 2019 году их рынок был довольно мал - всего 108 млн долл. Но из-за пандемии некоторые фирмы все активнее используют УФ-излучение. Например, шанхайская фирма Yanggao (общественный транспорт) превратила обычный моечный бокс в камеру дезинфекции с УФ-С-излучением для автобусов, сократив 40-минутный процесс до пяти минут. Предполагается что в дальнейшем УФ-С СИД найдут более широкое применение (рис. 3).

Производители УФ СИД обнаружили, что запросы клиентов на их продукцию за февраль 2020 года выросли в среднем более чем в пять раз. Например, фирма Seoul Viosys (Ансан, Республика Корея) при первоначальном размещении акций (IPO) столкнулась с тем, что за короткое время спрос на ее акции превысил предложение более чем в 900 раз [10].

Что касается ДУФ, то недавно корпорация Sensor Electronic Technology (SETi, Колумбия, Ю. Каролина) представила средство стерилизации, способное уничтожить вирус SARS-CoV-2 за 30 с. Утверждается, что за это время гибнет до 99, 9\% короновирусов. Тестирование было осуществлено совместно с Университетом Корё (Корейский университет, Сеул). При разработке дуФ СИД использовался сложный (составной) полупроводниковый материал, созданный SETi совместно с материнской корпорацией Seoul Viosys [20].

\section{Название Тип изделия \\ Краткая характеристика} компании

Medtronic Puritan Bennett ${ }^{\mathrm{TM}} 980$ (РВ980) стационарный аппарат ивл высокого класса

Medtronic Puritan Bennett ${ }^{\mathrm{TM}} 840$ (РВ840) -

\section{мощный комплекс ивЛ}

Пневматический; способ вентиляции - инвазивный / неинвазивный; вес аппарата 35 кг; есть возможность подключения источника кислорода

Предназначен для обеспечения естественного дыхания для пациентов весом от 0,5 до 150 кг; вес аппарата 18,2 кг; есть возможность подключения источника кислорода

\begin{tabular}{ll}
\hline Mindray & SynoVent E3 - \\
мощный аппарат Ивл
\end{tabular}

Оснащен цветным сенсорным ЖК-дисплеем (диагональ 10,4 дюйма), может работать в нескольких режимах вентиляции, подходит для использования в стационаре и при транспортировке

\begin{tabular}{ll}
\hline Philips & Trilogy $202-$ \\
& портативный аппарат Ивл
\end{tabular}

Предназначен для любой внутрибольничной транспортировки пациента; аккумулятор с зарядом на 3 ч работы; масса аппарата 5,6 кг

Университет штата Иллинойс (УрбанаШампейн)
Illinois RapidVent опытный образец аппарата экстренной ИВЛ
Аппарат может использоваться для оказания неотложной помощи больным COVID-19; образец проработал более 75 ч 
$\therefore *$

В предложенном кратком обзоре охвачены далеко не все возможности электронной промышленности по борьбе c COVID-19. Тем не менее надо отметить, что мировая электронная промышленность оказалась в высокой степени готова к пандемии. Во-первых, существуют обширные производственные мощности, которые можно быстро перенастроить на выпуск необходимой продукции. Во-вторых, подход проектирования на основе стандартизированных блоков, модулей и платформ существенно упрощает и ускоряет разработку новой продукции. В-третьих, доступен огромный рынок аттестованных сложно функциональныхблоков, в которых воплощена вся необходимая интеллектуальная собственность. В-четвертых, существует разветвленная сеть центров проектирования, оснащенных различными типами инструментальныхсредств САПР, способных быстро проектировать необходимые системы и их комплектующие. Главное, что проявляется в сложившейся ситуации - готовность быстрого реагирования различных отраслей промышленности, научного сообщества и органов власти на складывающуюся ситуацию, их совместная работа.

\section{ЛИТЕРАТУРА}

1. 实地街访：复工一周后的华强北商圈. 2020-02-28.

2. Nitin D. Infineon Withdraws 2020 Outlook as Industry Visibility Falls // EE Times. 03.26.2020.

3. Pelé Stop A-F. Cut or Maintain European Chip Production Amid Covid-19 // EE Times. 03.24.2020.

4. Jorgensen B. Supply Chain 101: The DPA Won't "Cure" Covid-19 // EE Times. 03.31.2020.

5. Fitzgerald A.M. and Khademolhosseini F. MEMS in the Fight Against Covid-19 // EE Times magazine. 04.01.2020.

6. Davis S. COVID-19 To Have Significant Effect on Worldwide Semiconductor Market in 2020, According to IDC // Semiconductor-digest. March 19. 2020.

7. Worldwide Server and Enterprise Storage Systems Markets Will Decline in 2020, Impacted by the COVID-19 Pandemic, According to IDC // Semiconductor Digest. March 27. 2020.

8. Davis S. Juniper Research: Coronavirus to Cause $\$ 42$ Billion Revenue Gap in Global Consumer Device Shipments over the Next 9 Months // Semiconductor-digest. March 26. 2020.

9. Medtronic Continuing to Increase Ventilator Production to Address COVID-19 Pandemic // Semiconductor Digest. March 26. 2019
10. Damianos D., Clerc S., Villien M., Mounier E., Boulay P. Coronavirus COVID-19 pandemic: How can technologies help to detect and stem the deadly virus? // I-Micronews. 03.19. 2020

11. Abbott launches molecular point-of-care test to detect novel coronavirus in as little as five minutes // I-Micronews. March 30. 2020

12. BioMérieux receives emergency use authorization for BIOFIRE ${ }^{\circledR}$ COVID-19 test // I-Micronews. March 24. 2020

13. Mesa Biotech receives emergency use authorization from FDA for a 30 minute point of care molecular COVID-19 test // I-Micronews. March 25. 2020.

14. Таиров Р. В Нью-Йорке зафиксировали 80\%-ную смертность среди подключенных к ИВЛ пациентов с коронавирусом Forbes. 9 апреля 2020.

15. Davis S. OnScale Launches Project BreathEasy: Digital Twins of Lungs to Improve COVID-19 Patients Outcomes // Semiconductor Digest. April 14.2020

https://www.semiconductor-digest.com/2020/04/14/onscalelaunches-project-breatheasy-digital-twins-of-lungs-to-improvecovid-19-patients-outcomes/

16. Synovent E3. Ventilators.

17. Respironics Trilogy 202

18. Illinois RapidVent Emergency Ventilator Developed for COVID-19 patients // Semiconductor Digest. April 1. 2020.

19. Medtronic Continuing to Increase Ventilator Production to Address COVID-19 Pandemic // Semiconductor Digest. March 26. 2019.

20. SETi's Violeds Technology Proves $99,9 \%$ Sterilization of Coronavirus (COVID-19) in 30 Seconds // Semiconductor Digest. April 2. 2020. 


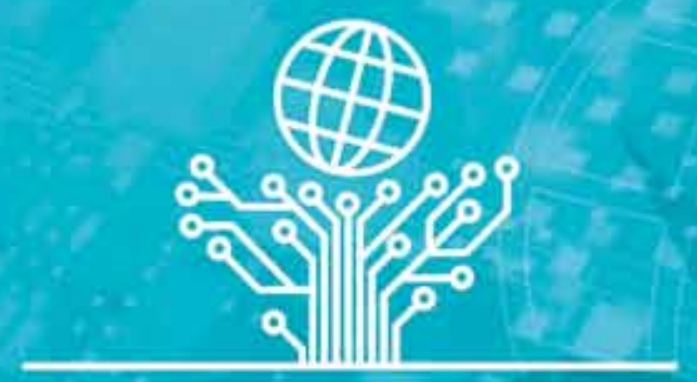

МЕЖДУНАРОДНЫЙ ФОРУМ

МИКРОЭЛЕКТРОНИКА-2020

28 сентября - 3 октября

Республика Крым, г. Ялта

\section{Международный Форум «Микроэлектроника 2020» -}

ключевое событие года в области микроэлектронных технологий

V Научная конференция «ӘКБ и микроэлектронные модули»

V Деловая программа $\quad \mathbf{V}$ Демонстрационная зона

$\mathbf{V}$ Фестиваль инноваций

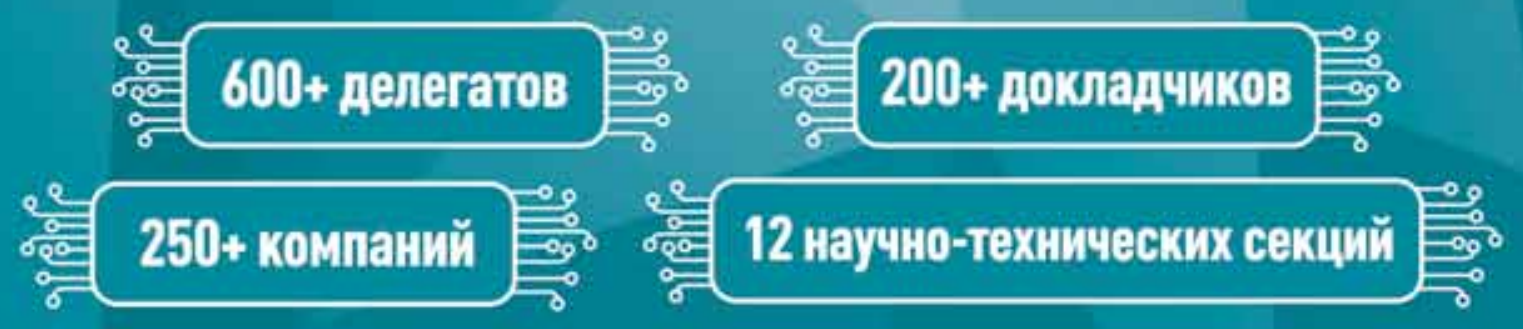

5 лет успешной работы

ПРИ ПОДДЕРЖКЕ

\section{МИнПРОмтоРГ РОССИИ

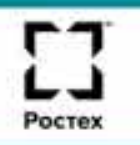

ОРГАНИЗАТОРЫ

\section{III) прогресс \& ниимэ кеуASIC}

ГЕНЕРАЛЬНЫЙ ИНФОРМАЦИОННЫЙ ПАРТНЁР

\section{(4D) TEXHOCФEPA}

Onератор Форума: Компания мПрофКонференции • Тел.:+7 (495) 641-57-17 • E-mail: info@microelectronica.pro Подробная информация и регистрация участников на официальном сайте Форума: microelectronica.pro 